\title{
On Solving the Business Requirements Engineering Problems of Information Systems Development Projects - Lessons from Three Projects
}

\author{
Dahlberg, Tomi \\ Turku School of Economics at the \\ University of Turku \\ Turku, Finland \\ tomi.dahlberg@utu.fi
}

\author{
Lagstedt, Altti \\ Turku School of Economics and \\ Haaga-Helia University of Applied \\ Sciences, Helsinki, Finland \\ altti.lagstedt@,haaga-helia.fi
}

\begin{abstract}
Information systems development (ISD) often fails. Requirements engineering ( $R E$ ) problems rank high in ISD project failure statistics. RE is often regarded as the link between business (processes) (BP) and IS. Thus, in RE, the BP and IS requirements need to be synchronized. We conducted three case studies to investigate RE problems and the reasons for them, especially to contemplate how to synchronize business process and IS development requirements in plandriven (waterfall) and change-driven (agile) projects. Investigated cases indicate that the ontological and epistemological matching of $I S$ and $B P$ requirements engineering methods improves requirements quality.
\end{abstract}

\section{Introduction}

Information Systems Development (ISD) projects have many known performance and business value problems. The business requirements of an IS often change during the lifetime of an ISD project. Projects exceed budgets and time schedules, and do not produce agreed functionalities. Outcomes fail to improve business execution, to meet business objectives and to deliver business value. In addition, business value is difficult to trace back to the developed IS [15, 41]. Standalone ISs have become rare as ISs are integrated into complex wholes and architectures with several ISs and data integrations [15, 41]. On the other hand, due to the all-pervading digitalization, the strategic significance of ISD appears to have increased anew as several organizations have recruited systems analysts and programmers after multiple decades' absence from ISD labor markets [3, 13]. The resource needs of ISenabled product, service and process development executed in-house and/or co-sourced with IS service vendors appear to motivate these recruitments.

IS development is typically carried out as ISD projects. Each ISD project is one-of-a-kind with project-idiosyncratic characteristics. An (ISD) project has a unique organization, resources, project tasks and objectives, even if ISD projects were executed with the same project management method as all other projects, such as Prince2 or PMBOK and/or the same ISD method such as SPICE or SAFe. Large projects are typically divided into sub-projects. Although subprojects are connected and may be synchronized, each sub-project is still also a unique project.

An ISD project is often a sub-project within a business development project together with a business process development (BPD) sub-project. The methods of ISD and BPD differ as do the professional backgrounds of typical IS and BP developers [8]. An organization could have independent ISD and BPD project teams, even within a single business development project. The comparison of related ISD and BPD sub-projects' requirements specifications could be the only discussion issue between the two sub-projects [8]. The synchronizing of project deliverables and time-tables during later project phases seldom results in shared re-engineering of or changes to sub-project requirements [8].

Prior studies have indeed revealed that the problems of requirements engineering (RE) are one of the most significant (ISD) project failure categories $[10,23,44]$ According to prior research, RE problems are primarily communication and collaboration problems [13, 20, 23]. Still, one logical conclusion is to emphasize the significance of rigid requirements engineering methods and practices (see e.g. [26, 40]) as a means to enhance (ISD) project success.

Although prior research has documented the connection between RE problems and ISD project failures, the connection between the RE in ISD and $\mathrm{BPD}$ projects has received less attention. We identified a research gap here. Are rigid (ISD and BPD) RE methods and practices enough? Or are there other factors that should be considered when RE methods and practices are used? If such factors are identified, is it possible to enhance RE methods and practices to 
partially or wholly eliminate the adverse impacts of those factors? The academic and practical significance of answering these questions motivates our study. In summary, the generic objective of the present article is to investigate the identified research gap and to find answers to questions raised above.

In our prior studies, we have shown the need to match the characteristics of ISD and BPD (methods) $[8,22]$. We reported the way in which matching deepens understanding regarding the findings of prior research, adds new insights, and helps practitioners to execute ISD (sub-)projects more successfully. Consequently, it is logical to extend this research idea of ISD and BPD method matching into the RE phases of those methods.

To achieve our objective, we conducted three case studies. The first case study was done in a large global corporation. In ISD, the corporation followed plandriven (waterfall, stage-gate) type ISD methods. Waterfall methods rely on a phased development process model with clear stage-gate decision points between successive project phases [7]. RE is one project phase. The corporation also used similar stagegate methods in BPD and project management. Thus, the epistemological and ontological natures of methods used were similar. The corporation wanted to improve the integration between BPD, ISD and their project management. RE was seen as a means to achieve this, since RE was expected to produce well-defined generic and detailed business and other requirements.

The two other cases followed change-driven (agile) ISD methods, namely Scrum and SAFe. One of the authors had participated in case 2 and another in case 3. We investigated ex post what factors created RE problems, and, on the basis of detected factors, proposed recommendations to improve RE success. The idea to match the characteristics of ISD and BPD requirements engineering in IS-enabling business development projects is the contribution of our study. From the backdrop discussed above, we formulated two specific research questions for this article:

RQ1: What factors - if any - caused requirements engineering problems in the investigated cases?

RQ2: What recommendations - if any - to avoid requirements engineering problems did the investigated cases offer, especially regarding the matching of IS and business process requirements engineering?

In the next section, we review requirements engineering literature on plan-driven and changedriven RE methods and practices within IS and business process development as the theoretical background of our study. We then present the cases and the methodology of data collection and analysis.
After that we report research findings, and end the article with a discussion and conclusions section.

\section{Theoretical Background}

The identification of business, technical, user and other requirements is the starting point of ISD. With RE we understand the process of defining, documenting and maintaining design requirements about the object of engineering, such as an IS [21]. In a project, requirements are elicited at the beginning of the project. All methods do so whether waterfall or agile [25]. Waterfall methods conduct RE at the beginning of a project, and re-plan the project, should requirements change. Agile methods produce an overall plan at the beginning, and continue RE through the entire lifecycle of the project to finetune the overall plan. In addition to IS literature, we review relevant organizational / business development literature similarly to what is done e.g. in [32].

\subsection{Requirements engineering and ISDMs}

During the 60-year history of ISD a myriad of ISD methods have been published. For example, the ISO/IEC JTC1 SC7 responsible for the international standardization of software and systems engineering develops and regularly updates over 300 standards. Still, the waterfall method by Royce [33] is probably the best-known ISD method.

The widely used waterfall method [43] is based on a phased IS life-cycle reference model [7]. Phases are separated and follow each other serially and linearly. In the waterfall method, phases are executed one by one, starting with the systems requirements analysis and definition phase, followed by system and software design, implementation and unit testing, integration and system testing, operation, and maintenance phases $[33,39]$. The move to the next phase requires that all activities of the previous phase have been completed and accepted. The acceptance decisions of prior phases are made at so called stage-gates with the activity called gating [7]. We call the waterfall and waterfalltype (ISD) methods as plan-driven methods. From an RE perspective, plan-driven methods are conceptually well-defined. RE is a distinct phase prior to design, implementation and other (ISD) project phases. Hence, plan-driven methods offer a straightforward way to develop ISs. Plan-driven methods also have several known limitations. For example, an early RE creates the risk of specification and design errors, which, if detected late, are difficult and expensive to correct. Even if the RE phase is carried out rigorously with IS requirements specified correctly, and even if the IS 
developed meets those requirements, it is possible that the IS is never taken into use. The ISD project failed. In these situations, requirements have changed entirely, making the IS obsolete [13, 39] and/or changes to business (processes) have been neglected in RE [8].

Since 1984, the Standish group has published annual Chaos reports that provide statistics about the success-rate of IS/IT projects during a year [15, 41]. An (ISD) project is deemed successful, if the project keeps to its time-table and budget, and delivers agreed functionalities. These project performance metrics are sometimes called the iron triangle of project success to distinguish them from business value metrics [18, 28, $37,45]$. The Standish group classifies projects into successful, troubled and failed [41]. Since only 15-35 $\%$ of projects have succeeded during any particular year (16,1 \% in 2019), Chaos reports also list project failure factors. We first looked at the 1995 Chaos report for two reasons. The waterfall method dominated ISD. Secondly, Schwaber and Sutherland presented the Scrum method in 1995 as an alternative to plan-driven ISD [36, 42]. The 1995 Chaos report identified 10 failure factors leading to ultimately cancelled projects: 1) incomplete requirements, 2) lack of user involvement, 3) lack of resources, 4) unrealistic expectations, 5) lack of executive support, 6) changing requirements and specifications, 7) lack of planning, 8) was not needed any longer, 9) lack of IT management, and 10) technology illiteracy [41]. Despite of the proliferation of agile ISDMs, the list is still the same in 2019 [41]. In addition to the first failure factor, failure factors 4, 6 and 8 are also clearly RE-related. Cumulatively, the evidence in the Chaos reports underlines the importance of rigorous and timely RE.

Academic researchers have discovered similar ISD project failure factors. They describe requirements and rigorous $\mathrm{RE}$ as the prerequisites of ISD project success (e.g. [10, 13, 23, 26, 44]. Some ISD project failure factors such as underestimating (business) changes, resourcing problems, communication and involvement problems, poor project and risk management, poor change management, and technology problems [26, 23, 44 ] are more or less related to RE. (ISD) projects differ significantly in size, duration, business criticality and other factors [27, 29]. Pinto and Mantel [28] noted that factors predictive of project failures vary widely depending upon the type of project.

During the last two decades change-driven ISD methods, most notably Scrum, DevOps and SAFe, have challenged plan-driven ISD methods with claims of being more flexible and better adapted to requirements changes. IS researchers have investigated these methods as a potential solution to the limitations of plan-driven methods [39, 43]. From the RE perspective, it is noteworthy that requirements could change during every sprint of a project. On the other hand, some recent studies report that solving the inflexibility challenge inherent in plan-driven methods has created new types of problems. For example, the scope and the requirements of an ISD project may grow or explode uncontrollably leading to technical instability, scaling and other performance problems, technical debt and/or to business process instabilities $[8,16,30]$. Consequently, rigorous RE is still needed.

One striking feature in the RE of plan- and changedriven ISD methods is the lack of established practices to synchronize and match ISD requirements to dynamically changing business strategy, and organizational and business process developments during the various phases / sprints / epics of ISD projects. It appears to us that the RE practice of ISDMs assumes that business strategy, business and organizations remain unchanged after initial RE. Change-driven ISD methods advocate the inclusion of the IS product owner, but the impacts of this practice are unclear. Business and organizational processes could also be developed independently of ISD. If BPD and ISD are sub-projects of a business development project, their time-tables, budgets and time-table estimates for deliverables are usually coordinated [8]. However, ISD and/or BPD methods do not require the integration of business and IS requirements nor do they consider the need for fit between the epistemological and ontological natures of methods used [8, 22]. Thus, as an example, a BPD sub-project could use a plandriven method and an ISD sub-project a change-driven method. This may lead to clashes or communication challenges (regarding requirements). Our prior studies $[8,22]$ discovered that the match between the epistemological and ontological natures of methods used increases the success probability of ISD projects. Here, we extend that proposition to the use of RE.

\subsection{The role, methods and practices of requirements engineering in ISD}

The role of ISD RE is to establish the link between IS developers and business professionals. Regardless of the ISD method used, there must be business needs prior to considering the execution of an ISD project. At the end of an ISD project, one of the final tasks is to evaluate how well business needs were achieved. The impacts of ISD RE specifications are thus significant throughout an ISD project [13, 23, 26, 34].

Business need is a vague concept. RE methods and practices are used to elicit business needs and to transform them into engineering requirements accurately and formally. In other words, RE aims to establish shared understanding about business needs and about how those needs should be realized in an IS. 
Requirements then guide ISD planning and the execution of an ISD project. In addition, requirements influence the priorities of development, testing and maintenance activities [38, 39, 40]. In change-driven ISD, requirements clarify ISD objectives from a user perspective. E.g., in the SCRUM method, the product owner collects user stories from project stakeholders and creates a list of these stories called the backlog. The backlog is used to select user stories for development in the beginning of each sprint [36]. In the SAFe method, each program increment ("sprint") implements specific user stories, which then create features and epics at higher IS architectural levels [34]. In summary, regardless of the ISD method used, requirements are the link between the real world and the developed IS $[10,23,44]$. However, ISD requirements are not matched with BPD requirements.

Sommerville and Sawyer [40] and Kotonya and Sommerville [21] proposed a model for the elicitation and analysis of requirements for plan-driven ISD. The underlying idea is that during the requirement elicitation phase, the purpose is to describe the full context of a need or a problem to be solved, such as its application domain, business context, stakeholders' expectations and constraints [21]. In change-driven ISD, the backlog in Scrum (and lean portfolio management with epics and programs in SAFe) are used for the same purpose [25].

During requirements elicitation, it is necessary to pay attention to the variation in the level of requirements. In the BABOK (Business Analyst Body of Knowledge) handbook, requirements are divided into strategic, tactical, and operational level requirements. Operational level requirements should be traceable from tactical level requirements and tactical level requirements from strategic level requirements. Strategic level requirements are typically wider and more abstract than tactical and operational level requirements [19]. The SAFe method advocates the use of the business model canvas re-labeled as portfolio canvas [34] for business RE. Hansen and Lyytinen [13] emphasized variation in requirement levels by dividing ISD project requirement challenges into individual cognitive challenges, interpersonal challenges, and complexity-based challenges, each of which reflects a particular level of requirements' abstraction. They claimed that RE research has focused (too much) on lower level abstractions at the expense of dealing with the challenges of broader systemic complexities 13].

Ideally, company level requirements prioritization is a part of (IS) project portfolio management. Portfolio management facilitates the pondering of requirements from a business strategy implementation perspective. Which business-critical requirements should be implemented next, which should be postponed, and which should be dropped? Project portfolio management also helps to decide how requirements are allocated to individual ISD projects [24]. On the other hand, project portfolio management does not ensure communication between projects, the matching of RE methods and practices between projects, nor the synchronization of BPD and ISD requirements.

How are requirements managed within a single ISD project? In the waterfall ISD, the assumption is that requirements do not change during a project after they have been specified and agreed to. Should requirements change, they are taken into an ISD project's steering committee meeting. The acceptance of changes means that the project is re-planned. Since re-planning has adverse time and resource impacts, change decisions are difficult to make [38, 39].

In change-driven ISD projects, continuous requirements engineering and changes are assumed. For example, the SAFe method combines DevOps ISD and lean management BPD methods, and could be seen to have the match advocated here. The use of SAFe (or Scrum) may, however, require the learning of a new vocabulary totally alien to business professionals. This increases the risk that all RE tasks are de-facto left to IS developers. IS developers are typically ISD experts that seldom have business management skills. Another risk is that RE is conducted with epistemologically and ontologically inconsistent methods and practices. In summary, change-driven ISD RE methods and practices face the risk that operational requirements are prioritized at the expense of strategic requirements. We propose that matching the characteristics of ISD and BPD RE improves the solving of this challenge.

\subsection{The role of business process development (BPD) in ISD}

The history of business process development goes back to 1911 and Frederick Taylor. He was the first to postulate the significance of "process thinking" [14]. An astonishing number of business (process) development models from alternative paradigms have been proposed ever since as Burrell and Morgan [5] describe. Organization and management theories have fundamentally changed our understanding about business processes, their development and significance. Business process management (BPM) and BPD methods have also absorbed intellectual content from operations research, quality control and IS research [14]. For example, the above reviewed ISD research has influenced the spreading of the Capability Maturity Model (CMM). The CMM was developed to ensure the quality of plan-driven IS development. The CMM Integration (CMMi) method then extended the use of the CMM to BPD. The important point is that due to 
the ever-increasing use of ISs the strategic importance of ISs continues to increase even in business areas, which traditionally have been considered low ISintensive [3]. Consequently, interactions between various $\mathrm{BPD}$ and ISD method traditions need to be considered, their RE methods and practices included.

Also, BPD methods and practices have evolved during the recent decades. Hammer and Davenport launched the business process re-engineering (BPR) concept in the early 1990s [11,9]. The proposition was that enterprises should not just automate processes but to redesign them in order to achieve radical process performance improvements. Large "destructive" BPR projects were discovered to have high failure risks, and BPR is now advocated as an episodic rather than an ongoing effort [12]. An emphasis on continuous process development management and diagnosis led to the introduction of the still evolving BPM concept and framework [1]. E.g., Rosemann and Vom Brocke [32] defined their BPM framework in 2010. Their framework has six core elements: strategic alignment, governance, methods, information technology, people, and culture. Each core element has five capability areas [32]. Similarities with the SAFe method's lean approach are obvious. If CMMi or BPM is used in a BPD (sub-)project that decision also influences RE.

BPD projects have traditionally been conducted with plan-driven development methods. In our opinion, BPM framework-based projects could also be executed as change-driven BPD projects. Lean management, used especially in manufacturing companies facilitates change-driven BPD projects.

In BPD, CMMi, BPR, BPM and lean management literature, IS/IT is considered closely related or even a part of process development. Yet the role of IS/IT is limited to providing support to process development for example to process design and modeling. ISs could also be used to control, manage and improve business processes with ISs purchased from IS service vendors [32]. Currently, however, the dependencies between ISD and BPD projects, their RE included, are not synchronized systematically and rigorously [31]. Our propositions - to synchronize the RE of ISD and BPD (sub)-projects, and to match ontologically and epistemologically the RE methods and practices of ISD and BPD used in particular projects - may require significant communicative and educational actions.

\subsection{Concluding remark; business-IT alignment}

As a summary: recent ISD and to some extent also BPD research acknowledges the significance of synchronizing requirements between related ISD and BPD (sub-)projects as well as the need to match the characteristics of the applied development methods so that the synchronization of requirements may happen. On the other hand, the practices and mechanisms on how of synchronizing BPD and ITD requirements in daily development work are currently little understood and/or do not exist. Only a few decades ago enterprises had a few isolated and independent ISs with a limited number of integrations. Master and other types of data were fragmented, and the strategic possibilities of IT and digital data were largely overlooked.

The business-IT alignment concept was introduced to address this need (see e.g. [17, 35]). This started a journey to the introduction of the digital strategy concept. Solid IS/IT capabilities are important for business process development. As discussed above the BPM concept does not automatically guarantee integration between business and IT $[4,6]$. The version 1.0 of the SAFe method was introduced only in 2011 and the current version 4.6 in October 2018. Safe includes the DevOps ITD method and the lean BPD method. SAFe method's strong ISD connotation still creates the risk that its use is primarily left to IS developers.

\section{Methodology}

According to Yin's classification the empirical part of our research follows the explorative case study strategy. That is, requirements engineering practices were investigated in the three cases without any beforehand formulated propositions [46]. The object of analysis [46] in each case was, how ISD and BPD requirements were managed in the investigated project and organization.

The global corporation of the first case has operations in over 200 locations in $70+$ countries and close to 20,000 employees. The enterprise has a large number of corporation-wide ISs in addition to business units' local ISs. The investigated project aimed to consolidate product data and the product data processes of the corporation into a single product data IS and process. The project and its requirements engineering were executed with plan-driven methods. We conducted data collection during 2009 and 2010 and data analysis in 2016 and 2019. We have investigated this case in our earlier study [8], but not from the requirements engineering perspective. As we deemed the amount of collected data extensive, carefully collected and analyzed, and as the investigated research problem had remained unchanged since 2010, we decided to revisit this data in 2019 from the requirements engineering perspective, since this issue had not been analyzed earlier. Our previous study [8] provides a detailed description of data collection and analysis methods, which we not repeat here. 
A university of applied sciences with over 10000 students and $30+$ educational programs, one-third international programs, conducted a change-driven project in 2014-2015. The university developed an IS for one of its new business areas. The objective was to later roll out the new IS to the other business areas. The project and its requirements engineering were executed with the Scrum method. We collected data in 2016 and analyzed it in 2016 and in 2019. Similar to case 1 , we have investigated this case previously, but not from the requirements engineering perspective.

A multi-ecosystem platform company automating the exchange of supply chain management (SCM) and logistics data is the third case. This company was established in 2018 to industrialize and commercialize the open source reference API and blockchain software developed in two research and one proof of concept projects during the years 2016 and 2018. The platform covers the SCM and logistics processes, and their data models that apply the UBL 2.X (ISO 19845) standard. Cumulatively over 40 process, maritime, finance and logistics industry enterprises participated in the three projects behind the platform. The requirements engineering for the platform was carried out with the SAFe method. We collected and analyzed data during spring 2019. Our role is different in cases 2 and 3 than in case 1 , since one author was actively involved in case 2 as the product owner and another author in case 3 as the lean portfolio manager.

We used three data collection sources of those in the Yin basket [46, p 106] in all cases: documentation, archival records and interviews. Direct observation and participant observation were also used in cases 2 and 3 . A contact person from the corporation helped us to organize interviews and to collect documents in case 1 . In that case, we conducted eight group-interview sessions and interviewed six persons individually after those sessions. The interviewees of the recorded events ranged from project to IT managers, and included the project owner and the responsible system architect. Business professionals were, however, underrepresented, which could not be avoided. In cases 2 and 3 we had access to full RE materials due to our roles in the projects. At the time of RE, we had no plan to conduct this research. Data was collected ex-post.

In case 1 , we prepared semi-structured interview questions for each session/interview and continued interviewing until saturation was reached. We asked interviewees to elaborate on their experiences with the various methods used in ISD and BPD projects. Our contact person and an information-gathering group screened documents before they were given to us in order to prevent access to business-critical product data. Altogether 95 different documents were analyzed, including project management guidelines, project reports, process models, taxonomies and planning documents. In cases 2 and 3, we had access to all case materials. The amounts of raw data were even larger.

During data analysis, two researchers examined data independently and separately. Findings were then compared and agreed upon by the researchers, discussed with a third researcher (case 1), and probed against the literature reviewed above. Finally, (in)consistencies in the collected sources of data were used to triangulate the data and the findings.

\section{Findings}

\subsection{Case 1 - RE in a plan-driven project}

The corporation of case 1 collected and prioritized business process improvement proposals continuously as a part of its business process management. A highly valued idea or proposal could start process maintenance or even trigger a new BPD project. Even though the collection and prioritization of improvement proposals was centrally managed by a small expert team, the company-wide RE process and the creation of proposals were distributed to business units. The objective was to avoid the execution of BPD projects in "silos" without a portfolio view on development initiatives executed within the corporation.

The project management practice of the case corporation was derived from the PMBOK method and hence the stage-gate model inherent in the PMBOK method was used. Related ISD projects were normally managed by the corporation's own personnel with project managers recruited mostly from the IT department. IS developers were usually acquired from outside IS supplier(s) for the duration of an ISD project. Because of this the requirements had to be collected and specified rigorously as well as defined comprehensively before offers were requested from outside IS vendors. All these plan-driven project characteristics leaned to waterfall type development.

There were seldom "pure" ISD projects. Instead of that, BPD and ISD sub-projects, with the objective to develop a business process, were usually executed simultaneously. The majority of requirements were taken from collected and prioritized business development requirements. Hence, ISD projects could have been carried out as the IS representations of changes made into business processes. However, we detected that requirements were typically allocated to specific ISD projects and were validated only against respective projects' ISD objectives. With this practice ties to the continuous collection and prioritization of business process requirements were cut and lost. Everything that was not in line with an ISD (sub- 
)project's scope was left out. The consequence was that the requirements of an ISD project were no longer pure business requirements but had transformed into technical ISD project requirements. We noticed that business professionals willingly and rapidly transferred the responsibility for these requirements to IT people as the language was no longer familiar to them. According to our analysis, this practice had significant adverse effects on ISD quality and success. The seriousness of adverse impacts increased if the project team members acquired from an IS vendor had limited experience in the developed business area, the relevant business process and/or the corporation.

ISD project team members usually had no direct personal-level contacts to the business professionals of the corporation - that is, to the future users of the IS. They had to rely on the quality of requirements specifications. In addition to that, a project team seldom had visibility to the work of other ISD project teams and/or to ISD and BPD carried out elsewhere. The consequences were that ISD project teams had difficulties in gaining overviews of related ISs and seldom understood the underlying business process improvement proposals, even if such overviews and understanding had been important and/or related to the work of the ISD project team. Some project teams perceived that their projects were carried out in "silos".

We also discovered that business units understood requirements engineering methods and practices differently. In most units, requirements were de facto managed by operational level IT department specialists. The involvement of business specialists and end users became limited after business requirements were allocated to ISD projects. In the ISD project investigated, the objective was to integrate and automate existing product data management processes. No need for business process development and related BPD RE was deemed necessary, although the need to improve the product data management process had initially triggered the ISD project. Although business process descriptions were accepted enterprise-wide, those descriptions were followed poorly. Employees handling product data had the freedom to carry out their daily tasks in their own way. In the investigated ISD project, only one standardized process was supported. This caused major operational troubles, since this process had not been implemented into local ISs and processes. The new IS was never put into use.

Our findings are in line with our proposed idea to match the RE of BPD and ISD methods. The significance of BPD requirements engineering was well understood in the case corporation, as the systematic collection of business process improvement proposals indicate. The need to synchronize business process and IS development requirements was also understood at a conceptual level. The epistemological and ontological nature of BPD, ISD and even project management methods matched. On the other hand, business requirements were entirely specified and documented prior to the start of ISD projects, and then handed over to IS developers recruited from external IS service providers. There were no RE or other practices to synchronize BPD and ISD requirements after requirements had been allocated to ISD projects and to IS developers. According to our analysis, the main reason for this was that (plan-driven) methods do not include such practices. The lack of RE synchronization had several adverse consequences, especially if the IS developers had limited contacts with business professionals and little experience of the engineered business process. In our opinion, the change of ISD method from plan-driven to changedriven would not have improved the situation unless also BPD methods and RE synchronization practices had been changed at the same time.

\subsection{Cases $2 \& 3-R E$ in change-driven projects}

The initial target of the BPD and ISD project of case 2 was to develop a minimum viable product (MVP) for thesis advisory management at the university of applied sciences. The objective was to learn about the new business area and its processes. Such insights could then be used to develop additional functionalities, to roll out the IS to other business areas, and to have a platform for future development. Primary user stories were collected and shortlisted to specify the first IS release (MVP). Technologies of the MVP were widely used in the university. BPD and ISD methods were also familiar as the university teaches them, although use and user experience with the Scrum method was limited. The development team was therefore built so that the development team skills matched with the technologies and the Scrum method. An IS contractor company with similar capabilities was recruited to conduct a co-sourcing ISD project.

New business needs were discovered soon after the project start. Consequently, the backlog of user stories increased rapidly and the architectural complexity of the IS started to grow. The project that had started as a small learning-type IS development project within a new business area with limited integrations to legacy ISs soon spiralled out to something different. The new process and IS were seen as highly valuable to the university if the IS could be rolled out to other business areas. The expectations of new stakeholders regarding the project scope and functionalities grew continuously. New requirements increased both business process and business value related uncertainties. It would have been necessary to increase 
the size, the scope and the resources of the ISD subproject as well, and to reconsider project objectives, applied technologies, integrations to legacy ISs as well as influences on and from other on-going (ISD) projects. Then the software contractor lost interest and quit. In the end, continued rapid increase of business requirements intertwined with technological challenges resulted in an ISD project failure and project discontinuation. The IS was later developed successfully, but that is beyond the scope of the current article. In a similar way to case 1 , doing things right was not enough. That is, the execution of RE and other ISD work according to the selected Scrum ISD method was not enough. Better continuous matching of BPD and ISD RE had been needed.

In case 3 , requirements were taken from the results of two academic projects and one development company proof-of-concept project. In these projects, approximately 40 companies from process, maritime and logistics industries together with their financiers investigated with researchers how to move from the manual exchange of SCM and logistics documents (i.e. from paper, Excel and pdf documents) to automatic and integrated exchange of electronic documents (data sets). In 2018, a multi-ecosystem company was established to industrialize and commercialize the results of the three projects. The key BPD and ISD requirements evolved into integrating supply chain and logistics process descriptions, data models and open source software into a single digital business ecosystem (DBE) platform. The platform facilitates the exchange of electronic SCM and logistics data, such as electronic order or waybill data between buyers, suppliers and other parties in need of the data. Platform usage is offered as a cloud service with a transaction fee business model. RE covered technical and business requirements. REST API and blockchain performance and data security are technical requirements examples. Platform governance arrangement and deployment of UBL 2.X (ISO/IEC 19845) data model standard in SCM business processes are business requirements examples. This BPD and ISD project was executed with the SAFe method as a co-sourcing ISD between the multi-ecosystem company and an international software service provider company.

In case 3, no serious requirements engineering problems had emerged by the launch date of the platform during the fall 2019. Data analysis, however, revealed two potential problem areas. Most experts of the multi-ecosystem company with business background were unfamiliar with the SAFe method, both DevOps and lean. Secondly, two business units from the software provider company were involved. One unit was responsible for software development (with SAFe) and another unit for cloud and data-center services (with the plan-driven ITIL). Risk mitigation of potential communication and culture problems caused by different methods and backgrounds have been used.

In summary, in cases 2 and 3 the epistemological and ontological basis of BPD and ISD requirements engineering matched to some extent. Despite of this, case 2 ran into $\mathrm{RE}$ problems caused by rapidly increasing business needs from new stakeholders. In case 3, possible future RE problems are also related to differences in stakeholder expectations and knowledge. The SAFe lacked useful guidelines. As a summary, we conclude that better methods and practices to synchronize BPD and ISD requirements are needed.

\section{Discussion and conclusions}

We discovered three answers to the first research question (RQ1). In all three cases, IS development was out- or co-sourced to IS developers acquired on project basis. The on-boarding of IS developers to ISD and especially to BPD sub-projects caused major requirements engineering problems in two cases and risks in the third case. IS developers had difficulties in understanding the case organizations' business and business processes, had participated in a limited way or not at all in the specification of business requirements prior to ISD projects, and had limited visibility to other ongoing ISD projects. Hence, IS developers had difficulties in understanding the requirements and in placing them correctly to business (process) development contexts. Secondly, limited or unexpected involvement of new business professionals caused RE problems. In case 1, after a thorough and rigorous business process improvement idea and requirements elicitation process, requirements were allocated to ISD projects with responsibility transfer to internal and external IS developers with limited followup. Best practice plan-driven methods do not recognize this issue. One interviewee from IT function described the consequences: "They (business professionals) say, you have been here so long that you should know our business deeply. That's ridiculous, since we are not involved in the daily execution of business." The investigated ISD projects and ISD experts worked in silos and communicated little with other ISD projects.

The findings of the present study support the matching of requirements engineering between IS and BP development as well as with the methods of other related development sub-projects and methods used in them. The findings of the three cases indicate consistently that the match is needed. This is our answer to RQ and also the most important result of our research. We discovered that currently knowledge about various best-practice methods, including the 
synchronization of requirements, is limited. Lack of knowledge was more visible in the two cases executed with change-driven methods.

We conducted each case study in a single organization and each case was unique in multiple ways. These are the main limitations of our study. As the number of cases is three and as each case is different, individual case findings need to considered tentative, cannot be compared and should be cautiously interpreted. On the other hand, our findings augment prior research and are in line with our experience as academics and practitioners. We have witnessed and heard similar requirements engineering problem stories several times over the years. Thus, even some of the individual case findings are interesting and may open new venues for future RE research. In case 1, the lack of synchronization after an ISD project was started is such an individual finding. In case 2, the rapid escalation of ISD project complexity caused by requirements explosion is a similar finding. The possible consequences of poor method understanding in case 3 are also noteworthy.

In case 1 , data analysis beyond the case revealed that the successes and problems of RE varied significantly from project to project. Our conclusion is that RE methods (e.g. requirements elicitation) and practices (e.g. allocation of requirements to projects) alone are unable to ensure that RE problems would not occur or that (ISD) projects would be successful. At the same time, the epistemological and ontological stances of IS, business process and other deployed development methods determine how RE is conducted. The findings of our cases offer three tentative conclusions regarding requirements engineering in ISD projects. The matching of epistemological and ontological stance of methods used in ISD and other related development (sub-)projects appears to increase the probability of RE and project success. Secondly, rigorous and careful synchronization of requirements between related sub-projects (e.g. ISD and BPD subprojects) during the life-cycle of the main project appears to increase the probability of RE and project success. Finally, RE is often executed partially or wholly prior to the start of an ISD project. When external IS developers are used to develop the IS, activities that help them to understand the origin and significance of requirements in proper business context appears to increase the probability of RE engineering and project success. We offer these conclusions as our recommendations to practitioners.

Our conclusions and recommendations to practitioners are at the same time amenable to future research. In our opinion, there is a research gap in how to synchronize and match business process and IS development. The rapid development and proliferation of new, mainly change-driven, ISD and BPD methods makes such research valuable to both academics and practitioners. Furthermore, understanding the suitability and limitations of various RE methods and practices should be improved. One possible research avenue is to develop selection models for RE and ISD method selection to various development contexts. Another possible research idea is to analyze the outcomes of various methods. Future research could also find solutions to RE problems at an enterprise level. Our study contributes to research with the conducted review over the theoretical background of $\mathrm{RE}$, individual case study findings, and especially with the empirically validated idea to seek a match between BPD and ISD RE methods and practices.

\section{References}

[1]Van Der Aalst, W. M. P., ter Hofstede, A. H. M., and Weske, M. 2003. "Business Process Management: A Survey," Business Process Management, pp. 1-12.

[2] Ahonen, J. J., and Savolainen, P. 2010. "Software Engineering Projects May Fail before They Are Started: Post-Mortem Analysis of Five Cancelled Projects," Journal of Systems and Software (83:11), pp. 2175-2187.

[3] Borg, M., Olsson, T., Franke, U., and Assar, S. 2018. "Digitalization of Swedish Government Agencies - A Perspective Through the Lens of a Software Development Census," in International Conference on Software Engineering.

[4] Broadbent, M., Weill, P., and St.Clair, D. 1999. "The Implications of Information Technology Infrastructure for Business Process Redesign," MIS Quarterly (23:2), pp. 159182.

[5] Burrell, G., and Morgan, G. 1979. Sosiological Paradigms and Organisational Analysis, Farnham, Surrey, England: Ashgate Publishing Limited.

[6] Cleven, A. 2011. "Exploring Patterns of Business-IT Alignment for the Purpose of Process Performance Measurement," in Proceedings of the 19th European Conference On Information Systems (ECIS), pp. 1-12.

[7] Cooper, R. G. 1990. "Stage-Gate Systems : A New Tool for Managing New Products," Business Horizons (MayJune).

[8] Dahlberg, T., and Lagstedt, A. 2018. "There Is Still No " Fit for All 'IS Development Method: Business Development Context and IS Development Characteristics Need to Match," in Proceedings of the 51st Hawaii International Conference on System Sciences.

[9] Davenport, T. H., and Short, J. 1990. "The New Industrial Engineering: Information Technology And Business Process R ...," Sloan Management Review (31:4), pp. 11-27.

[10] Dwivedi, Y. K., Wastell, D., Laumer, S., Henriksen, H. Z., Myers, M. D., Bunker, D., Elbanna, A., Ravishankar, M. N., and Srivastava, S. C. 2015. "Research on Information Systems Failures and Successes: Status Update and Future Directions," Information Systems Frontiers (17:1), pp. 143157. 
[11] Hammer, M. 1990. "Reengineering Work: Don't Autmate, Obliterate," Harvard Business Review (JulyAugus), pp. 104-112.

[12] Hammer, M. 2010. "What Is Business Process Management?," in Handbook on Business Process Management 1, J. vom Brocke and M. Rosemann (eds.), Berlin, Heidelberg: Springer Berlin Heidelberg, pp. 3-16. [13] Hansen, S., and Lyytinen, K. 2010. "Challenges in Contemporary Requirements Practice," Proceedings of the Annual Hawaii International Conference on System Sciences, pp. $1-10$.

[14] Harmon, P. 2010. "The Scope and Evolution of Business Process Management," in Handbook on Business Process Management 1, J. vom Brocke and M. Rosemann (eds.), Springer Berlin Heidelberg, pp. 37-82.

[15] Hastie, S., and Wojewoda, S. 2015. "Standish Group 2015 Chaos Report - Q\&A with Jennifer Lynch," InfoQ, Blog.

[16] Heikkilä, V. T., Lassenius, C., Damian, D., and Paasivaara, M. 2015. "A Mapping Study on Requirements Engineering in Agile Software Development," in Software Engineering and Advanced Applications (SEAA), 2015 41st Euromicro Conference On, IEEE, pp. 199-207.

[17] Henderson, J. C., and Venkatraman, H. 1999. "Strategic Alignment: Leveraging Information Technology for Transforming Organizations," IBM Systems Journal (38:2.3), pp. 472-484.

[18] Ika, L. A. 2009. "Project Success as a Topic in Project Management Journals," Project Management Journal (40:4), pp. 6-19.

[19] International Institute of Business Analysis. 2009. “A Guide to the Business Analysis Body of Knowledge (BABOK)," Toronto, Canada.

[20] Jantunen, S., R. Dumdum, and D.C. Gause, "Towards New Requirements Engineering Competencies", Proceedings of the 12th International Workshop on Cooperative and Human Aspects of Software Engineering, (2019), 131-134.

[21] Kotonya, G., and Sommerville, I. 1998. Requirements Engineering: Processes and Techniques, John Wiley \& Sons. [22] Lagstedt, A., and T. Dahlberg, "A Contingency Theory Motivated Framework to Select Information System Development Methods", Pacific Asia Conference on Information Systems, (2018), 1-14.

[23] MacManus, J., and Wood-Harper, T. 2007. "Understanding the Sources of Information Systems Project Failure," Management Services (51:3), pp. 38-43.

[24] MacMillan, I. C., and McGrath, R. G. 2002. "Crafting R\&D Project Portfolios," Research Technology Management (45:5), pp. 48-59.

[25] Melegati, J., A. Goldman, F. Kon, and X. Wang, "A model of Requirements Engineering in Software Startups", Information and Software Technology 109, 2019, pp. 92107.

[26] Nelson, R. R. 2007. "IT Project Management: Infamous Failure, Classic Mistakes, and Best Practices," MIS Quarterly Executive (6:2), pp. 67-78.

[27] Petter, S., DeLone, W., and McLean, E. R. 2012. "The Past, Present, and Future of 'IS Success,'" Journal of the Association for Informaiton Systems (13), pp. 341-362.
[28] Pinto, J. K., and Mantel, S. J. 1990. "The Causes of Project Failure," IEEE Transactions on Engineering Management (37:4), pp. 269-276.

[29] Pinto, J. K., and Slevin, D. P. 1988. "Project Success: Definition and Measurement Techniques," Project Management Journal (19:3), pp. 67-73.

[30] Rodríguez, P., Haghighatkhah, A., Lwakatare, L. E., Teppola, S., Suomalainen, T., Eskeli, J., Karvonen, T., Kuvaja, P., Verner, J. M., and Oivo, M. 2017. "Continuous Deployment of Software Intensive Products and Services: A Systematic Mapping Study," Journal of Systems and Software (123), pp. 263-291.

[31] Rosemann, M. 2010. "The Service Portfolio of a BPM Center of Excellence," in Handbook on Business Process Management 2, J. vom Brocke and M. Rosemann (eds.), Berlin, Heidelberg: Springer Berlin Heidelberg, pp. 267-284. [32] Rosemann, M., and vom Brocke, J. 2010. "The Six Core Elements of Business Process Management," in Handbook on Business Process Management 1 (2nd ed.), J. vom Brocke and M. Rosemann (eds.), Springer Berlin Heidelberg, pp. $107-122$.

[33] Royce, D. W. W. 1970. "Managing the Development of Large Software Systems," Ieee Wescon (August), pp. 1-9.

[34] SAFe 2019. "SAFe Home".

[35] Sallé, M. 2004. "IT Service Management and IT Governance: Review, Comparative Analysis and Their Impact on Utility Computing."

[36] Schwaber, K., and Sutherland, J. 2017. "The Scrum Guide.”.

[37] Shenhar, A. J., Dvir, D., Levy, O., and Maltz, A. C. 2001. "Project Success: A Multidimensional Strategic Concept," International Journal of Project Management (34:6), pp. 699-725.

[38] Sommerville, I. 1996. "Software Process Models," ACM Computing Surveys (28:1), pp. 269-271.

[39] Sommerville, I. 2011. Software Engineering, (9 $9^{\text {th }}$ ed.), Boston, Massachusetts: Addison-Wesley.

[40] Sommerville, I., and Sawyer, P. 1997. Requirements Engineering A Good Practice Guide, West Sussex: John Wiley \& Sons Ltd.

[41] Standish Group. 1995, 2015, 2019 "The CHAOS Report," The CHAOS Report (1995, 2015, 2019).

[42] SCRUM 2019. "The Official Scrum Guide" (https://www.scrumguides.org)

[43] Theocharis, G., Kuhrmann, M., Münch, J., and Diebold, P. 2015. "Is Water-Scrum-Fall Reality? On the Use of Agile and Traditional Development Practices," in International Conference on Product-Focused Software Process Improvement (Vol. 9459), pp. 149-166.

[44] Verner, J., Sampson, J., and Cerpa, N. 2008. "What Factors Lead to Software Project Failure?," in Proceedings of the 2nd International Conference on Research Challenges in Information Science, RCIS 2008, pp. 71-79.

[45] de Wit, A. 1988. "Measurement of Project Success," International Journal of Project Management (6:3), pp. 164170.

[46] Yin, R. K. 2014. "Case Study Research: Design and Methods," (5th ed.), Applied Social Research Methods Series, Sage Publications. 